\title{
Homophily in Collaborations among US House Representatives, $1981-2018$
}

\author{
Zachary P. Neal, Rachel Domagalski, Xiaoqin Yan \\ Michigan State University
}

\begin{abstract}
Effective lawmaking requires collaboration among legislators, who form coalitions to advance their legislative agendas. In this paper, we explore how legislators' party and gender identities simultaneously influence whom they choose as collaborators by examining differential party and gender homophily during a period of shifting party control and increasing representation of women in the US House of Representatives. We introduce new methods for inferring legislative collaboration networks from bill co-sponsorship data, then estimate crosssectional logistic regression models on these networks from $1981-2018$. We find evidence of differential homophily by both party and gender: Republicans and women tend to prefer same-party and same-gender political collaborators more than Democrats and men. However, party homophily (i.e., partisanship) is stronger than gender homophily, suggesting that party is a more salient identity for legislators than gender.

This is a pre-print. For the final published version of record, see:

Neal, Z. P., Domagalski, R., \& Yan, X. (2022). Homophily in collaborations among US House Representatives, 1981-2018. Social Networks, 68, 97-106. https://doi.org/10.1016/j. socnet.2021.04.007
\end{abstract}

Keywords: backbone, bipartite projection, gender, homophily, partisanship, political networks

\section{Introduction}

Effective lawmaking requires collaboration among legislators, who form coalitions to advance their legislative agendas (Aref \& Neal, 2020; Finke, 2012). In the US Congress these collaborations have become increasingly polarized into 5 two ideologically-opposed groups along partisan lines (Neal, 2020; Moody \& Mucha, 2013), however recent research has suggested that partisanship may be

Email addresses: zpneal@msu.edu (Zachary P. Neal), domagal9@msu.edu (Rachel Domagalski), yanxiaoq@msu.edu (Xiaoqin Yan)

Preprint submitted to Social Networks

February 18, 2022 
stronger among some parties than others (Grossmann \& Hopkins, 2015). At the same time, as the percent of women in the House of Representatives has grown more than four-fold between 1981 and 2018, there is increasing attention 10 directed toward the role that gender plays among political elites (Lovenduski, 1998; Wangnerud, 2009; Thomsen \& King, 2020). However, findings remain mixed about the extent to which gender shapes legislative collaboration (e.g., Fischer et al., 2019; Wojcik \& Mullenax, 2017; Craig et al., 2018; Papavero \& Zucchini, 2018; Cook, 2011; Bratton \& Rouse, 2011).

15 In this paper we explore how legislators' party and gender identities simultaneously influence whom they choose as collaborators by examining differential party and gender homophily during a period of shifting party control and increasing representation of women. We introduce new methods for inferring networks of legislative collaboration from data on bill co-sponsorship. We then

20 apply these methods to data from each legislative session of the US House of Representatives from 1981 - 2018, and examine these legislative collaboration networks by estimating a series of logistic regressions. We find evidence of differential homophily by both party and gender: Republicans and women tend to prefer similar same-party and same-gender political collaborators more than 25 Democrats and men.

The paper is organized in four sections. We begin by briefly reviewing the literature on legislative networks, focusing on the micro-level processes of party homophily (i.e., partisanship) and gender homophily. In the second section, we discuss the use of bill co-sponsorship to infer legislative collaborations, and 30 introduce several innovations on the stochastic degree sequence model (SDSM; Neal, 2014). Fitting a series of logistic regression models to inferred collaboration networks during each session from 1981 to 2018, in the third section we present estimates of differential party and gender homophily in collaborative tie formation. Finally, we conclude by discussing the implications of the in-

35 terplay between party and gender homophily in legislative collaboration on the legislative process.

\section{Legislative networks}

For more than a decade, legislative networks have shed new light on understanding legislative behavior (Fowler, 2006a,b). Rather than attempt to provide 40 a comprehensive review of legislative networks (see Ringe et al., 2016), here we focus on reviewing answers to three key questions in this literature: What do legislative networks explain, what do legislative networks measure, and when does collaboration form?

Although legislative networks clarify that governance is an interactive and

45 interdependent process, they are most useful if they help us explain or predict key parts of this process. The most consequential action a legislator can take is voting, and several studies have shown that a legislator's position in a legislative network helps explain their voting behavior. For example, Fowler (2006a) found that US legislators were more likely to vote in favor of bills sponsored by

50 well-connected legislators, even after controlling for shared party membership, 
and therefore that well-connected legislators were more effective at advancing their legislative agendas. Similarly, Ringe et al. (2013) found that social ties among European legislators exacerbated ideological voting patterns: friendship increased the likelihood of political allies voting the same way, but decreased 55 the likelihood of political adversaries voting the same way. Fong (2020) offers one potential explanation for the network's influence over voting behavior: "When legislators are called on to vote on a question that they do not understand, they take cues from experts who are nearby in the legislative network" (p. 270). Although voting is particularly consequential, legislative networks

60 have also been used to explain how the coalitions that shape voting outcomes change over time. For example, Neal (2020) demonstrated that the US Congress has become substantially more partisan since 1973 with legislators increasingly collaborating only with members of the same party, and opposing members of the other party. However, Koger et al. (2016) and Aref \& Neal (2020) clarified

65 that these coalitions are not strictly partisan and frequently include members from both parties.

Directly measuring legislative networks (e.g., simply asking legislators who they work with) is challenging because legislators are busy and may have motivations to conceal or misrepresent their true collaborations. As a result, most

70 studies of legislative networks rely on more indirect measurements derived from bill sponsorship (e.g., Neal, 2020), committee memberships (e.g., Porter et al., 2005), attendance at press events (e.g., Desmarais et al., 2015), and roll call votes (e.g., Andris et al., 2015). What do such indirectly measured legislative networks measure? Different source data provides information about different 75 types of relations among legislators. For example, voting similarly in roll call votes provides information about ideological alignment, whereas sharing membership on a committee provides information about alignment on prioritized issues. The majority of legislative networks are derived from patterns of bill sponsorship, which also provides information about ideological and issue align80 ment, but more directly provides information about collaboration as legislators join together in lending their collective support to bills (Kirkland, 2011; Kessler \& Krehbiel, 1996).

All but the most popular legislative measures require collaboration to cultivate support and ensure their eventual passage. Past studies have identified

85 many factors that influence when legislators choose to collaborate, consistently finding support for homophily (McPherson et al., 2001): similar legislators are more likely to collaborate (Caldeira \& Patterson, 1987). These factors include political party and gender, which we discuss in greater detail below, but also include sharing locations (e.g., Baller, 2017; Bratton \& Rouse, 2011; Fischer 9o et al., 2019; Aleman \& Calvo, 2013), committees (e.g., Baller, 2017; Fischer et al., 2019), interest groups (e.g., Fischer et al., 2019; Aleman \& Calvo, 2013), and race or ethnicity (e.g., Bratton \& Rouse, 2011; Craig et al., 2018). For example, across several different national legislative contexts, studies have consistently found that legislative collaboration (as measured by bill co-sponsorship)

95 is more likely between legislators from neighboring districts (in Argentina; Aleman \& Calvo, 2013), nearby districts (in nine US states; Bratton \& Rouse, 
2011), the same member state (in Europe; Baller, 2017), and same-language regions (in Switzerland; Fischer et al., 2019). Drawing on these past findings of homophily, but motivated by intensifying partisanship and increasing representation of women in the US Congress, we focus on the roles of party and gender in greater detail.

\subsection{Party homophily}

In the context of legislative collaboration, homophily with respect to political party is known as partisanship, which when particularly intense leads to parti-

105 \& Mucha, 2013) and media reports (e g. Ingraham, 2015) confirm that polarization has become a hallmark of legislative relations in the US Congress, so observing party homophily in networks of legislative collaboration is expected. However, the more nuanced phenomenon of asymmetric polarization remains understudied from the perspective of networks and homophily.

Asymmetric polarization occurs when some political parties are more partisan than others, which has been documented in the United States in both the popular press (e.g., Orstein, 2014; McCarty, 2014) and research (e.g., Grossmann \& Hopkins, 2015). For example, McCarty (2014) explained that "despite 115 the widespread belief that both parties have moved to the extremes, the movement of the Republican Party to the right accounts for most of the divergence between the two parties." Grossmann \& Hopkins (2015) trace this asymmetry to functional differences between these two parties, explaining that "the Republican Party is primarily the agent of an ideological movement whose sup120 porters prize doctrinal purity, while the Democratic Party is better understood as a coalition of social groups seeking concrete government action" (p. 119). Viewed through a network lens, asymmetric polarization is equivalent to differential homophily, wherein the extent to which Republican legislators prefer to collaborate with other Republican legislators differs from the extent to which 125 Democratic legislators prefer to collaborate with other Democratic legislators. However, although network data and models have been used to study polarization, they have not yet been exploited to study asymmetric polarization. In this study, based on past findings of asymmetric polarization, we expect to observe evidence of differential homophily by party, such that homophily will be

\subsection{Gender homophily}

Although there is a long history of research documenting gender homophily across a wide range of social interactions (e.g., Brashears, 2008, 2015; McPherson et al., 2001), the lack of representation of women in legislatures has made the 135 investigation of gender homophily in legislative collaboration impossible. However, as women's representation in legislative chambers has increased, attention has turned to understanding the potential role of gender in shaping legislative collaboration (e.g., Lovenduski, 1998; Schmitt \& Brant, 2019; Wangnerud, 2009). Some have suggested there may be politically strategic reasons to de- 
(Anzia \& Berry, 2011), introduce more legislation, and keep sponsored bills alive longer (Volden et al., 2013). In contrast, others have found that attracting men and conservative colleagues to co-sponsor legislation on issues of particular concern for women either has no effect or reduces its likelihood of passage (Shim, 2020), and that prioritizing such legislation can reduce a legislator's chance of re-election (Shim, 2021). Perhaps owing to the historically small numbers of women in legislative bodies, research on the role of gender in legislative outcomes in general, and as we describe below on the role of gender in legislator collaborations in particular, remains mixed.

Some studies have found evidence of gender homophily among legislators. For example, Fischer et al. (2019) found that co-sponsorships were more likely between same-gender than different-gender Swiss legislators. However, this pattern may be stronger for women than men, pointing to a differential gender homophily effect. In both Brazil (Wojcik \& Mullenax, 2017) and the United States (Craig et al., 2018), women were more likely to collaborate with women, but there was no similar tendency among men. Several studies have suggested that gender homophily in general, and among women legislators in particular, may be driven by differences in policy priorities. Specifically, some have argued (see Russell (2021) for an alternative perspective) that women place higher pri${ }_{160}$ ority on legislation related childcare, gender equality, and reproductive health (Schwindt-Bayer, 2006; Fouirnaies et al., 2019; Swers, 1998; Shim, 2020, 2021), which leads them to engage in collaborations with one another on these bills, often even crossing party lines (Clark \& Caro, 2013; Swers, 2005). Others have suggested that gender homophily may be driven by ideological tendencies. For example, Barnes (2012) found that the ideologies of pairs of women from the same party were more similar than mixed-gender pairs from the same party, while Thomsen (2015) argues that women (including Republican women) tend to be more liberal.

In contrast, other studies have failed to observe gender homophily among 170 legislators. For example, Baller (2017) observed that same-gender legislators in the European parliament were not significantly more likely to co-sponsor legislation together than different-gender legislators. Similarly, Papavero \& Zucchini (2018) found that "Italian women MPs do not behave as a cross-party interest group" (p. 259). In the United States, the effect of gender homophily has been mixed, appearing statistically significant in some years (Cook, 2011) or in some states (Bratton \& Rouse, 2011), but not others. Barnes (2012) contends that these mixed findings may be partly a methodological artifact: most studies of gendered legislative behavior analyze roll call votes, which is so "highly structured by part discipline" that "few intraparty differences emerge" (p. 484). Because past findings have been mixed, we have no specific expectations concerning gender homophily among legislators in the US House of Representatives. However, by examining a period $(1981-2018)$ and legislative chamber (US House of Representatives) that has seen a dramatic increase in the number of women, and using co-sponsorship rather than roll call vote data, we expect that these analyses will reveal gender homophily if it is present. 


\section{Methods}

\subsection{Bill co-sponsorship data}

Data on legislators' collaborative relationships is difficult to collect directly from legislators because they are busy and may have particularly strong incen190 tives to provide socially desirable or politically strategic responses. Therefore, most research on legislative networks relies on indirect data (Ringe et al., 2016), for example, inferring legislators' collaborations from their committee memberships (e.g., Porter et al., 2005), press events (e.g., Desmarais et al., 2015), or roll call votes (e.g., Andris et al., 2015). However, bill co-sponsorships remain the most widely used data for inferring legislative networks (e.g., Aleman \& Calvo, 2013; Baller, 2017; Bratton \& Rouse, 2011; Clark \& Caro, 2013; Craig et al., 2018; Fischer et al., 2019; Fowler, 2006a,b; Kirkland, 2011, 2014; Kirkland \& Gross, 2014; Micozzi, 2014; Neal, 2014, 2020; Rippere, 2016; Tam et al., 2010; Zhang et al., 2008).

In the US Congress, the legislative process begins when a legislator or group of legislators draft a bill and introduce it for consideration in either the House of Representatives or Senate. The legislator whose name appears first on the bill is known as the "sponsor," while other legislators who have also joined to support the bill, either at the time of its initial introduction or later in the legislative 205 process, are known as "co-sponsors." In this analysis, we restrict our focus to bills and joint resolutions because only these types of legislation have the force of law if passed, and we make no distinction between a bill's first-named "sponsor" and its subsequently listed "co-sponsors" because the sponsor is not necessarily the person who conceived, drafted, or championed the bill during the legislative process (Wilson \& Young, 1997; Neal, 2020; Campbell, 1982; Koger, 2003).

Legislators' co-sponsorship behaviors are a potentially rich source of information about legislative collaboration for several reasons. First, decisions about which bills to co-sponsor are also decisions about whom to join as a co-sponsor. Thus, a co-sponsorship is a overt expression of interest in working with other co-

215 sponsoring legislators to advance a bill through the legislative process (Kessler \& Krehbiel, 1996). Second, although only a small fraction of bills are ultimately voted on, all bills including trivial and controversial ones are available for cosponsorship. Thus, co-sponsorship decisions capture a much broader range of position-taking and collaboration-building behaviors than does voting (Highton

220 \& Rocca, 2005; Schiller, 1995; Barnes, 2012). Finally, a large number of bills are introduced in each session, but each legislator co-sponsors only a small fraction of them. Thus, although co-sponsorship decisions may not have the same legal force as roll call votes, they nonetheless require picking and choosing what and whom to support. Table 1 reports descriptive characteristics of the bill

225 co-sponsorship data for each session, including the number of legislators and bills, as well as the mean number of bills co-sponsored per legislator and mean number of co-sponsors per bill. 


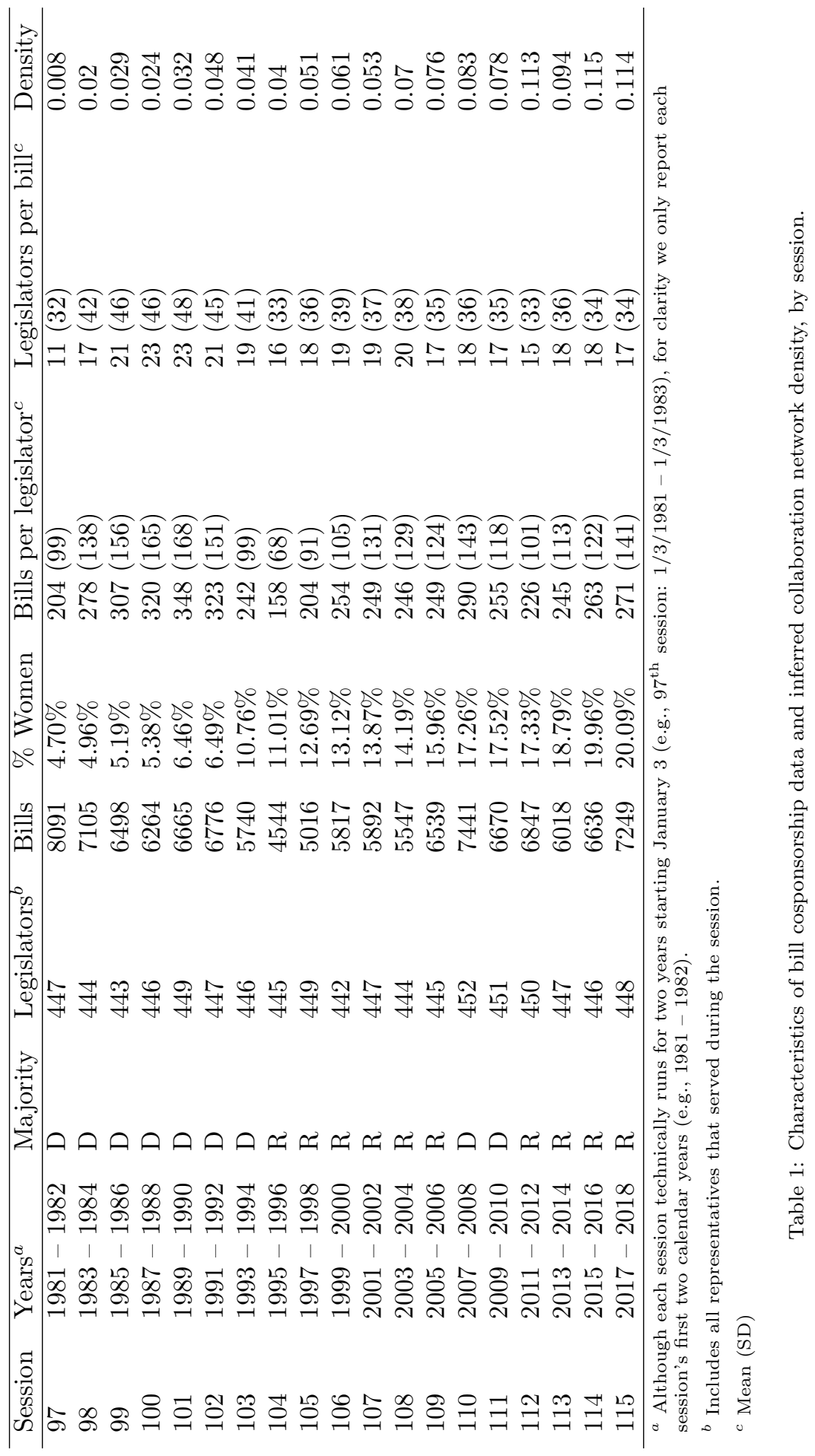




\subsection{Inferring legislative collaboration networks}

The data on bill co-sponsorships in a given session and chamber take the 230 form of a bipartite matrix $\mathbf{B}$, with a row for each legislator and column for each bill, where $B_{i k}=1$ if legislator $i$ sponsored or co-sponsored bill $k$, and otherwise is 0 . When used to measure a network of legislative collaboration, typically these data are transformed into a weighted adjacency matrix $\mathbf{P}$ via bipartite projection (i.e., $\mathbf{B B}^{T}=\mathbf{P}$; Breiger (1974); Neal (2014)), where $P_{i j}$ equals the number of bills that legislators $i$ and $j$ co-sponsored together. Studies of co-sponsorship networks often stop here, either analyzing $\mathbf{P}$ as a weighted network, or converting it to an unweighted network by applying a universal threshold or other rule-based dichotomizing threshold (e.g., Fong, 2020; Bratton \& Rouse, 2011). However, a pair of legislators' shared co-sponsorships cannot be 240 directly interpreted in this way. What counts as a 'large' number of shared cosponsorships differs for each pair because different legislators sponsor different numbers of bills (i.e., there is substantial variation on the row sums of $\mathbf{B}$ ), and the bills they sponsor have been sponsored by different numbers of legislators (i.e., there is substantial variation on the column sums of $\mathbf{B}$; see Table 1). These variations are particularly important in an analysis focused on gender because prior research has demonstrated that there are gender differences in the number (Schwindt-Bayer, 2006; Spirou, 2017; Volden et al., 2013; Schmitt \& Brant, 2019; Gagliarducci \& Paserman, 2016; Anzia \& Berry, 2011) and type (Clark \& Caro, 2013; Schwindt-Bayer, 2006; Fouirnaies et al., 2019; Swers, 2005; Shim, 2020, 2502021 ) of bills sponsored. For this reason, we infer legislative collaborations from bill co-sponsorships using the stochastic degree sequence model (SDSM; Neal, 2014), which controls for these variations.

The SDSM retains edges in the weighted bipartite projection $\mathbf{P}$ that are statistically significant by comparing them to distributions of edge weights generated by a null model. In the SDSM's null model, the particular bills sponsored by each legislator are random, but the number of bills sponsored by each legislator (i.e., the row sums) and number of legislators sponsoring each bill (i.e., the column sums) are approximately constrained to their values in the observed data. The construction of null edge weight distributions under SDSM's null model involves three steps. First, the probability that legislator $i$ sponsored bill $k$ is estimated, typically using a binary outcome model such as logit (Neal, 2020) or scobit (Neal, 2014; Schoch \& Brandes, 2020). Second, the probability distribution for the number of joint co-sponsorships between legislators $i$ and $j$ is constructed, typically via numerical simulation (Neal, 2020; Schoch \& Brandes, 265 2020). Finally, each edge's weight is tested against against a corresponding null distribution, retaining edges if their weights are statistically significantly large at a predefined $\alpha$ significance level; here, we use the conventional $\alpha=0.05$. Here, although we adopt the SDSM, we introduce improvements to each of these three steps. These extensions to the SDSM are implemented in the backbone package for R (Domagalski et al., 2021a). Additional information on how the backbone package works and the mathematics behind the SDSM model is provided by Domagalski et al. (2021b) and Neal et al. (In press). 
First, we estimate a bipartite probability matrix $\mathbf{B}^{*}$, in which $B_{i k}^{*}$ is the probability that legislator $i$ co-sponsors bill $k$, under the conditions that legislator $i$ 's total expected number of co-sponsorships is equal to his or her observed total number of co-sponsorships (i.e., $\left.E\left(\sum_{k} B_{i k}^{*}\right)=\sum_{k} B_{i k}\right)$, and bill $k$ 's total expected number of co-sponsors is equal to its observed total number of co-sponsors (i.e., $\left.E\left(\sum_{i} B_{i k}^{*}\right)=\sum_{i} B_{i k}\right)$. Earlier implementations of the SDSM have estimated this matrix using logistic regression (Neal, 2014, 2020; Schoch \& Brandes, 2020), however here we introduce a more accurate approach that relies on convex optimization. We first consider the set of all 0-1 $m \times n$ matrices with the same row and column sums as $B$ as vectors in $\mathbb{R}^{m n}$. We call this set of vectors $A$ and consider the convex hull of $A, \operatorname{conv}(A)$. A set is convex if for any two points in the set, the line connecting them is also in the set. The convex hull is the smallest convex set containing $A$. The $\operatorname{conv}(A)$ is the set of all matrices in $\mathbb{R}^{m n}$ with the same row and column sums as $B$, but with entries restricted between the values 0 and 1 . From this set of matrices, we find one that maximizes the entropy function

$$
H(M)=\sum_{i, j}\left(M_{i j} \ln \frac{1}{M_{i, j}}+\left(1-M_{i j}\right) \ln \frac{1}{1-M_{i j}}\right)
$$

on $\operatorname{conv}(A)$ and use this matrix's entries as the probabilities $B^{*}$. The Bipartite Configuration Model (BiCM) (Saracco et al., 2015, 2017) offers a numerically equivalent method for obtaining these probabilities; because it is more computationally efficient, it is the method implemented in the backbone package (Domagalski et al., 2021a).

Second, given these probabilities, we construct the probability distribution for the number of bills jointly co-sponsored by a pair of legislators $i$ and $j$ under the null model. Earlier implementations of the SDSM have constructed an approximate probability distributions via numerical simulation (Neal, 2014, 2020; Schoch \& Brandes, 2020), however here we construct exact probability distributions by observing that they follow Poisson binomial distributions (Liebig \& Rao, 2016) ${ }^{1}$. The probability that legislators $i$ and $j$ both sponsored bill $k$ is $B_{i k}^{*} \times B_{j k}^{*}$. We now want to find the probability of two legislators sponsoring at least $\ell$ bills together where $\ell=P_{i j}$. To do this, we consider the probabilities under the projection which has the Poisson binomial distribution. Since $P=B^{*} B^{* T}$, we have

$$
P_{i j}^{*}=B_{i 1}^{*} B_{j 1}^{*}+B_{i 2}^{*} B_{j 2}^{*}+\cdots+B_{i n}^{*} B_{j n}^{*} .
$$

Thus $P_{i j}^{*}$ is Poisson binomial with parameters $p_{1}=B_{i 1}^{*} B_{j 1}^{*}, \ldots, p_{n}=B_{i n}^{*} B_{j n}^{*}$. From these probabilities, we are interested in finding the cumulative distribution

\footnotetext{
${ }^{1}$ Although Liebig \& Rao (2016) suggested using the Poisson binomial distribution in this case, their equation (6) for computing the probability that two given primary nodes are connected to a given secondary node can sometimes yield numbers great than 1 . We provide a correct proof here.
} 


\subsection{Analytic plan}

Characterizing the level of homophily observed in a network requires considering each group's relative prevalence and controlling for individuals' opportunities (or lack thereof) to form homophilous relationships. We compute descriptive metrics of homophily for each gender and party group as

$$
\frac{\text { observed number of within-group edges }}{\text { expected number of within-group edges }},
$$

where the expected number assumes that edges are distributed randomly.

Although this approach provides a descriptive summary of a group's homophilous tendency controlling for the opportunity structure, it does not conmophily that is attributable to group membership rather than other factors. For example, observing that Republicans are homophilous could occur if Republicans actually are homophilous, but could also occur if men are homophilous and tend to be Republicans. To determine the association between group memstatistical model. We considered several different approaches to modeling these 
data $^{2}$, and here present the results from a series of cross-sectional logistic regression models to estimate the strength of homophily among men, among women, among Republicans, and among Democrats.

For each session we estimate the presence or absence of a legislative collaboration between two legislators $i$ and $j$ as a function of several dyadic characteristics using the following logistic regression:

$$
\begin{gathered}
\operatorname{logit}\left(P\left(\text { Collaboration }_{i j}=1\right)\right)=\beta_{0}+ \\
\beta_{1} \text { BothMen }+\beta_{2} \text { BothWomen }+ \\
\beta_{3} \text { BothRepublican }+\beta_{4} \text { BothDemocrat }+ \\
\beta_{5} \text { SameState }+\beta_{6} \sqrt{\mathrm{dsp}}+\beta_{7} \min (\text { degree })+\epsilon
\end{gathered}
$$

320 In this model, each of the four 'Both' terms is a binary variable indicating whether $i$ and $j$ share the characteristic (e.g., BothRepublican $=1$ if both $i$ and $j$ are Republicans, and otherwise is 0$).^{3}$ The coefficients associated with these terms $\left(\beta_{1}-\beta_{4}\right)$ estimate the differential homophily effect associated with this characteristic and are the primary coefficients of interest. ${ }^{4}$

The remaining terms are included as statistical controls and to improve model fit, but are not of direct theoretical interest. The $\beta_{0}$ coefficient captures the overall probability of an collaboration between $i$ and $j$, and therefore the density of the network. The 'SameState' term is a binary variable indicating whether legislators $i$ and $j$ represent the same state, and therefore estimates ho330 mophily in legislative collaborations with respect to state. The 'dsp' term measures the number of partners shared by $i$ and $j$ (i.e., dyadwise shared partners) and is included to model tendencies toward transitive closure; if two legislators have collaborations with many of the same others, they are likely to collaborator with each other. Finally, the ' $\min$ (degree)' term measures the minimum 35 degree of $i$ and $j$ and is included to model tendencies toward isolates; if either member of a dyad has a low degree, they are unlikely to form a collaborative relationship. ${ }^{5}$. Because parametric standard errors and associated p-values are

\footnotetext{
${ }^{2}$ The size of the networks, number of waves, and number of 'joiners' and 'leavers' between waves made stochastic actor oriented models (SOAMs; Snijders, 1996) or temporal exponential random graph models (TERGMs; Desmarais \& Cranmer, 2012b) impractical, while cross-sectional exponential random graph models (ERGMs; Hunter et al., 2008) failed to converge. We ruled out bipartite exponential random graph models (BERGM; Wang et al., 2013) because our research questions concern legislators' collaborations with each other, but not on specific bills. Finally, we ruled out generalized exponential random graph models (GERGMs; Desmarais \& Cranmer, 2012a) because the edge weights in our weighted bipartite projections can not be interpreted as indicating the strength of a legislative collaboration.

${ }^{3}$ Legislators who did not affiliate as either Republicans or Democrats were coded as a member of the party with which they caucus.

${ }^{4}$ The inclusion of these variables is intended to mimic the inclusion of nodematch (diff=TRUE) terms in an ERGM.

${ }^{5}$ The inclusion of each of these variables is intended to mimic a corresponding ERGM term: the $\beta_{0}$ parameter mimics the edges term, 'SameState' mimics a nodematch term, 'dsp' mimics the gwdsp term, and ' $\min$ (degree)' mimics the isolates term
} 
biased, we evaluate each coefficient's statistical significance by comparison to 1000 Monte Carlo quadratic assignment procedure (QAP) permutations, computed using the netlogit command in the sna R package (Butts, 2019).

We evaluate the model's goodness-of-fit in each session in two ways. First, we compute several common model-based fit indices, including Nagelkerke's pseudo- $\mathrm{R}^{2}$ (Nagelkerke, 1991), the percent change in model deviance computed as

$$
\left(\frac{\text { Null Deviance - Residual Deviance }}{\text { Null Deviance }}\right) \text {, }
$$

and the prediction accuracy computed as the percent of dyads that the model correctly predicts. These values range from 0 to 1 and captures the extent to which the model's predictions match the observed presence and absence of legislative collaborations. Second, we adopt an ERGM-like approach to evaluate 345 network-based model fit by examining the similarity of each observed network to a distribution of simulated networks generated using the estimated coefficients. This network-based model fit evaluation involves three steps. First, we use the fitted logistic regression coefficients to compute the predicted probability of a collaboration between $i$ and $j$. Second, we construct a simulated legislative collaboration network by treating each edge as the outcome of an independent Bernoulli trial with the given probability. Third, we compute three structural characteristics in this simulated network: degree, dyadwise shared partners, and geodesic distance. Finally, we repeat steps two and three 1000 times, then compare the distribution of these three characteristics in the observed network 355 to the $10^{\text {th }}-90^{\text {th }}$ percentile range across the 1000 simulated networks.

The data and code needed to replicate these analyses are available at https: //osf.io/xba82/.

\section{Results}

\subsection{Descriptive homophily metrics}

Before turning to the model estimates, it is useful to first consider the level of homophily observed among party and gender groups controlling for the opportunity structure. Figure 1 shows the extent to which Republicans' (red), Democrats' (blue), men's (light blue), and women's (pink) observed homophily exceeds what would be expected if collaborative relationships formed randomly

365 among legislators. As expected, we observe that legislators form relationships along party lines, with both Republicans and Democrats choosing co-partisan collaborators more often than would be expected if collaborations formed randomly. However, the pattern differs for women and men: Women choose other women as collaborators more often than would be expected at random, but men do not. This pattern is also expected, and illustrates the role of opportunity structure. The majority of legislators in the US House are men, so even if collaborations form randomly, the majority of collaborations will be between two men. Accordingly, observing many collaborations between two men is unsurprising and not evidence of homophily among men. Conversely, because so 


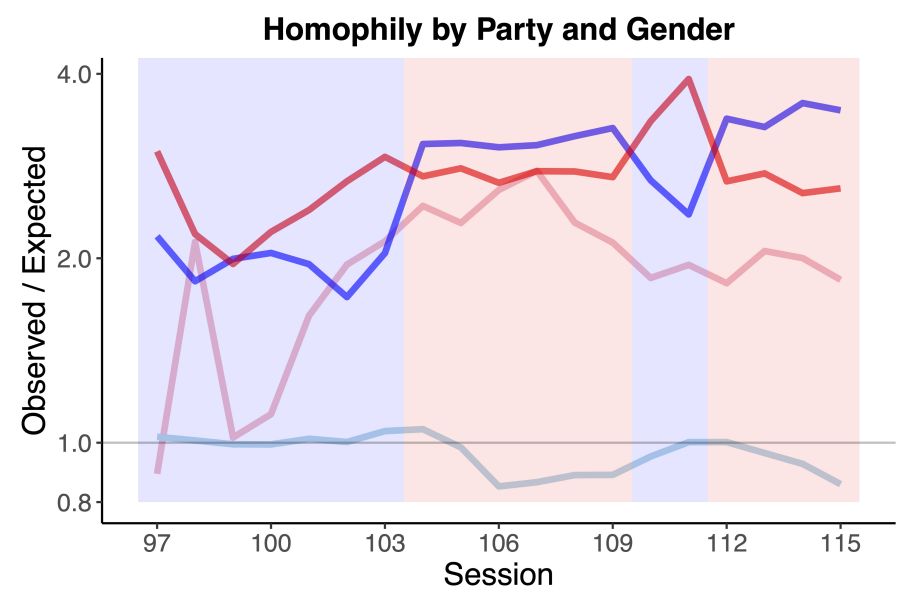

Figure 1: Extent of homophily among Republicans (red), Democrats (blue), men (light blue), and women (pink), by session of Congress. The background is blue if Democrats held a majority during the session, and red otherwise.

few legislators in the US House are women, observing even a few collaborations between two women provides evidence of homophily. However, although these descriptive metrics are informative, they do not necessarily indicate the true homophilic tendencies of these groups because they do not control for other correlated covariates. For example, although women appear to exhibit a strong tendency to collaborate with other women, these metrics do not disentangle how much of this apparent tendency can be attributed to being a women versus being a Democrat, which is common among women legislators.
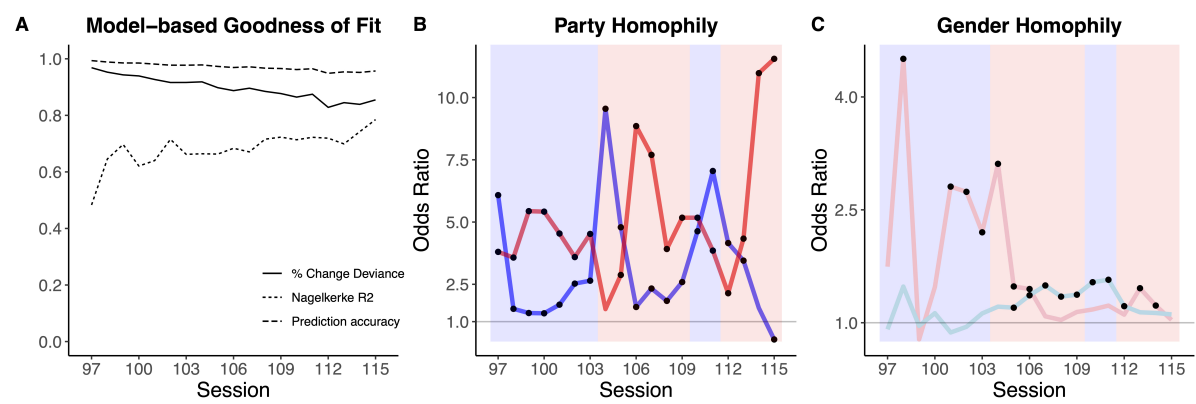

Figure 2: Logistic regression results by session: (A) Model-based goodness of fit; (B) Party homophily and party control; (C) Gender homophily and women's representation. $\bullet p<0.05$ 


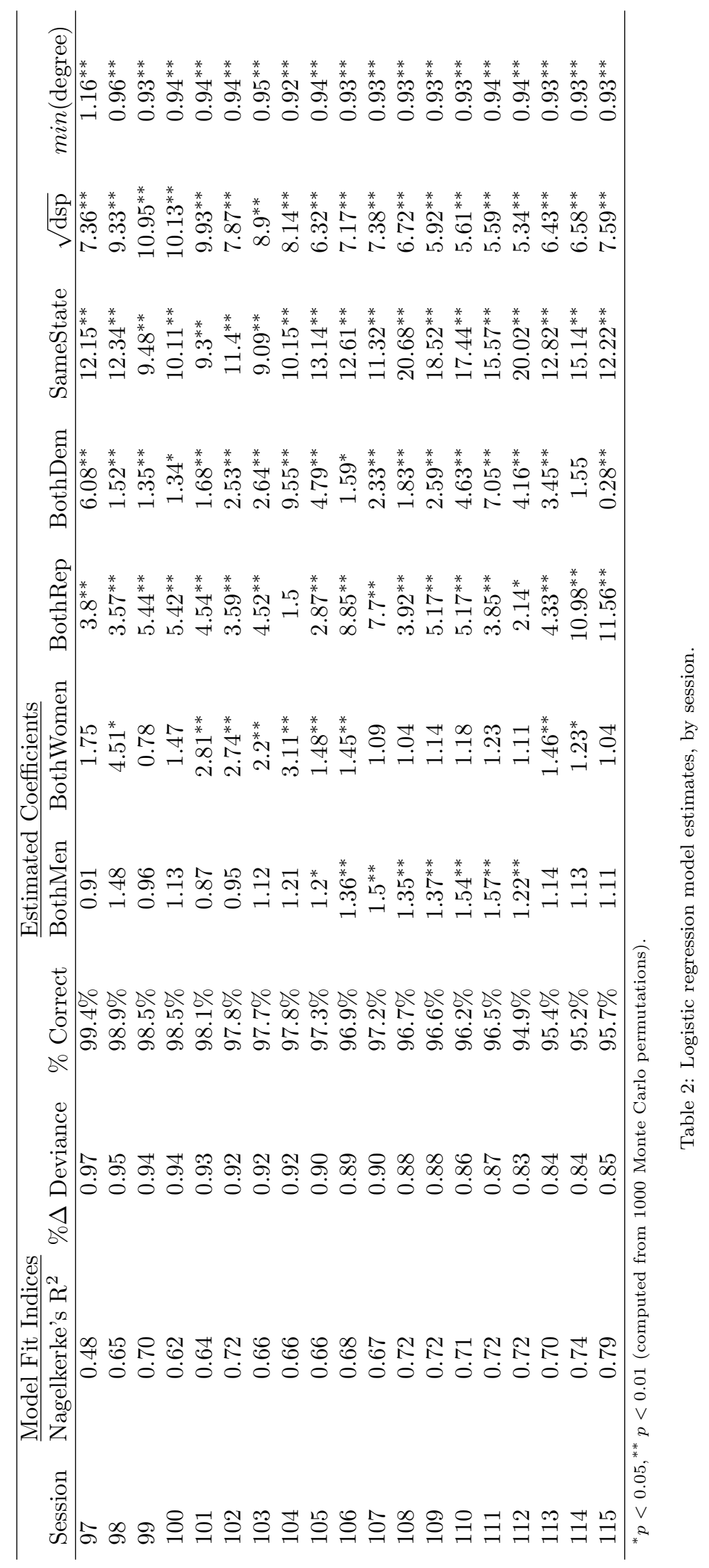



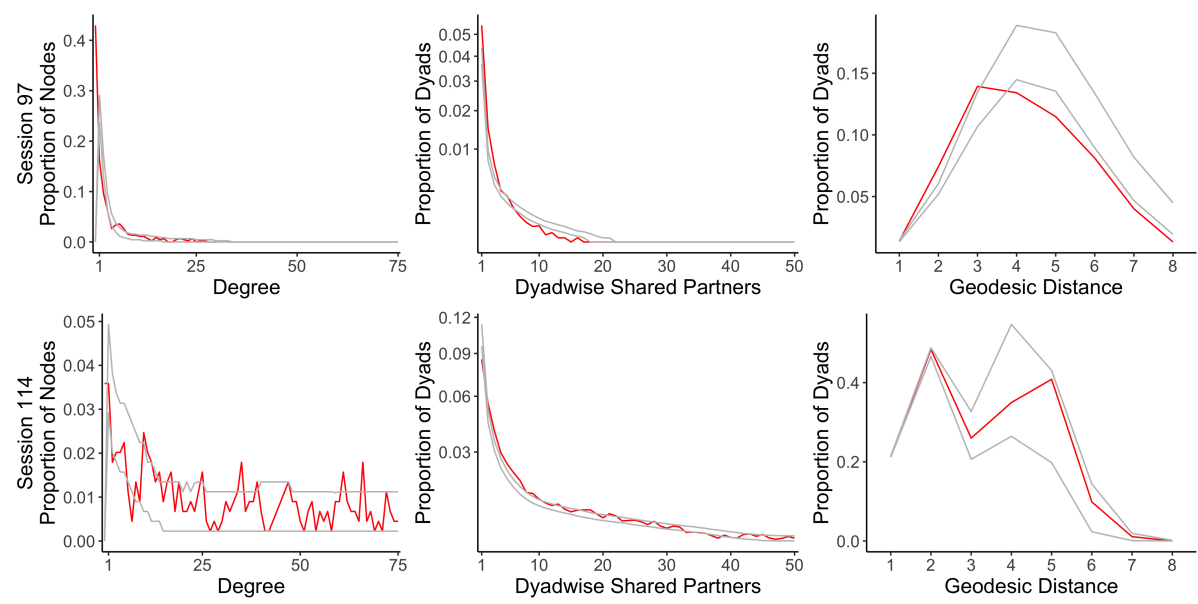

Figure 3: Network-based goodness of fit in the $97^{\text {th }}$ (top) and $114^{\text {th }}$ (bottom) sessions.

\subsection{Model Fit}

The first several columns of Table 2 report three model-based indices of fit (Nagelkerke's pseudo- $\mathrm{R}^{2}$, the percent change in deviance, and prediction accuracy), while Figure 2A plots these indices over time. Each of these indices is relatively large and suggest good model fit. Figure 3 shows two assessments of network-based fit, illustrating the similarity of the observed $97^{\text {th }}$ (top) and $114^{\text {th }}$ (bottom) session networks to 1000 simulated networks generated by the respective models' coefficients. In both cases, the observed network's degree distribution, dyadwise shared partner distribution, and geodesic distance distribution generally falls within the $10^{\text {th }}$ and $90^{\text {th }}$ percentile of the simulated networks. Plots for other sessions exhibit similar patterns and are available at available at https://osf.io/xba82/. Together, the model-based and network-based as395 sessments of fit indicate that the estimates obtained via logistic regression both exhibit reasonable fit to the data and describe generative processes that produce networks with structures similar to the observed networks.

\subsection{Party Homophily}

Table 2 reports parameter estimates with Monte Carlo-based statistical significance for each session of Congress. The estimates of party homophily are illustrated in Figure 2B, which shows the odds ratio describing the strength of homophily among Republicans (red line) and Democrats (blue line) in each session; estimates that are statistically significant at $\alpha=0.05$ are marked with a black dot. For example, in the $114^{\text {th }}$ session, a Republican was 10.98 times more likely to collaborate with another Republican than with a Democrat $(p<0.01)$, while a Democrat was only 1.54 times more likely to collaborate with another Democrat than with a Republican (not significant). This plot also shows the 
party holding the majority in the U.S. House of Representatives during each session, with Republican majorities indicated by red shading and Democratic majorities indicated by blue shading. Over the period under investigation, control of the chamber switched three times, first from Democratic to Republican in the $104^{\text {th }}$ session in the "Republican Revolution" that ended a long stretch of post-war Democratic control that began in 1955, then back to Democratic in ${ }_{415}$ the $110^{\text {th }}$ session, and finally to Republican again in the $112^{\text {th }}$ session.

These estimates of party homophily exhibit several patterns that are consistent with prior research (e.g., Grossmann \& Hopkins, 2015). First, as expected, both parties exhibit strong tendencies toward homophily. On average a legislator is 4.21 times more likely to engage in a partisan collaboration than a bi-

${ }_{420}$ partisan collaboration. Second, there is evidence of asymmetric polarization in the form of differential homophily. Across these 19 sessions, although the party that exhibits a stronger tendency toward partisan collaborations shifts over time (e.g., Democrats in the $104^{\text {th }}$ session, but Republicans in the $106^{\text {th }}$ session), the strength of Republicans' preference for collaborating with other Republicans differs from the strength of Democrats' preference for collaborating with other Democrats (one-sample t-test of difference: $t[18]=5.47, p<0.001$ ). Third, Republicans (Mean $\mathrm{OR}=5.21$ ) have a statistically significantly stronger tendency toward partisanship than Democrats (Mean OR $=3.21$; Welch's two-sample t-test: $t[35.179]=2.42, p=0.021)$, consistent with prior literature on asymmet-

430 ric polarization (Grossmann \& Hopkins, 2015). Finally, but in contrast to prior findings of increasing polarization (e.g., Neal, 2020; Moody \& Mucha, 2013), we observe no evidence that the strength of Republicans' $(\rho=0.279, p=0.247)$ or Democrats' ( $\rho=0.086, p=0.726)$ homophily is increasing.

\subsection{Gender Homophily}

Table 2 reports parameter estimates with Monte Carlo-based statistical significance for each session of Congress. The estimates of party homophily are illustrated in Figure 2C, which shows the odds ratio describing the strength of homophily among men (light blue line) and women (pink line) in each session; estimates that are statistically significant at $\alpha=0.05$ are marked with a black

440 dot. For example, in the $110^{\text {th }}$ session, a man was 1.54 times more likely to collaborate with another man than with a woman $(p<0.01)$, while a woman was only 1.18 times more likely to collaborate with another woman than with a man (not significant).

These estimates suggest that legislators exhibit homophily with respect to gender when they form collaborations. First, both genders exhibit tendencies toward homophily. On average a legislator is 1.47 times more likely to collaborate with a same-gender colleague than with a different-gender colleague. Second, there is evidence of differential gender homophily. Across these 19 sessions, although the gender that exhibits a stronger tendency toward homophily shifts ${ }_{450}$ over time (e.g., women in the $104^{\text {th }}$ session, but men in the $110^{\text {th }}$ session), the strength of mens' preference for collaborating with other men differs from the strength of womens' preference for collaborating with other women (one-sample t-test of difference: $t[18]=3.76, p=0.0014)$. Third, women $($ Mean $\mathrm{OR}=1.73)$ 
have a statistically significantly stronger tendency toward homophily than men Women, Democrats, and Republicans act on opportunities to collaborate with members of their own group, while men are so numerous that they have limited opportunities for exhibit notable levels of homophily (see Figure 1). However, effects offers a more complex story about the role these identities play in the formation of collaborations.

Political parties are influential in the US Congress, and as expected (e.g., Layman et al., 2006), we find evidence of partisanship (i.e., party homophily; see 490 Figure 2B). Moreover, we observe evidence of asymmetric polarization (i.e., differential party homophily) that is consistent with past research (e.g., Grossmann \& Hopkins, 2015), wherein Republicans are significantly more likely to engage in partisan collaborations than Democrats. Together these findings confirm that partisanship is present and strong, however contrary to some prior reports (e.g., 495 Neal, 2020), we do not find evidence that its intensity is increasing. Prior research has been less clear about the role of gender in legislative collaborations, with some work finding that gender matters (e.g., Fischer et al., 2019; Wojcik \& 
Mullenax, 2017; Craig et al., 2018), other work finding it does not (e.g., Baller, 2017; Papavero \& Zucchini, 2018), and still others finding that it depends (e.g., Cook, 2011; Bratton \& Rouse, 2011). We find evidence of gender homophily in the formation of legislative collaborations, and observe statistically significant differences between women and men (see Figure 2C). Specifically, we observe that on average women have a stronger tendency toward homophily in their legislative collaborations than men, but that the strength of their homophily

The discrepancies between the intensity of homophily estimated by consider-
has ing only one group membership (Figure 1) versus by considering group membership in the context of other group memberships and structural effects (Figure 2) may point to subtle mechanisms of collaboration formation. Although women appear to be homophilous when considering gender alone, they appear much less homophilous when gender is considered in the context of other factors. Of particular relevance is the fact that, because women have difficulty winning congressional races as Republicans, the majority of women in these sessions of Congress were Democrats Thomsen (2015). The decline in homophily among women after controlling for party may indicate that when women collaborate, this collaboration is driven only partly by activating their gender identity, but also by activating their partisan identity. Similarly, although both Republicans and Democrats appear to be uniformly homophilous when considering party alone, there is more variation when party is considered in the context of other factors. This may suggest that when members of the same party collaborate, they do so partly as co-partisans, but also by collaborating with collaboratorsof-collaborators, who are also likely to be co-partisans. That is, a process of transitive closure may partly account for observed levels of partisanship.

Although we find that both party and gender matter for forming legislative collaborations, homophily is particularly strong among Republicans. Controlling for several demographic and structural characteristics, we find that in 13 of the 19 sessions homophily among Republicans was stronger than homophily among Democrats, among men, and among women. This is consistent with past claims that "Republicans have consistently valued doctrinal purity over pragmatic deal-making" (Grossmann \& Hopkins, 2015, p. 119). That is, when legislators seek collaborators on the floor of the US House of Representatives, identity as a Republican is particularly influential. Taken together, these findings provide a nuanced picture of the processes involved in the formation of legislative collaborations. Gender is sometimes a salient identity, but plays a weaker and more inconsistent role than party, which is a more consistently salient identity. It is surprising that the increasing representation of women in the US House has not led gender to play a greater role. Indeed, the fact that gender plays a modest role highlights the dominance of party affiliation as legislators' primary identity. If political party remains legislators' primary identity, undiluted by potentially competing or intersecting identities such as gender that could bridge ideological differences, this may facilitate a more entrenched polarization in which the 'us versus them' fault lines become uncrossable.

These findings and their implications for polarization must be viewed in light 
of some important limitations. First, we examine networks of legislative collaborations that have been inferred from bill co-sponsorships rather than measured directly, and which therefore may not accurately capture the true relations of collaboration on the floor of the US House. Second, although these data are longitudinal, for practical reasons we have adopted a repeated cross-sectional modeling strategy. As a result, our ability to examine longitudinal trends is 550 restricted to observing changes in each wave, but not directly estimating these trends. These two limitations point to the need for future research to replicate these findings using more direct measurements of collaboration and models that can more effectively capitalize on these data's longitudinal characteristics.

The modeling approach we applied also has some strengths and potential weaknesses compared to more conventional ERGM and SAOM approaches. A key strength is that, unlike an ERGM (which failed to converge) or SAOM (for which these data are too large), logistic regressions are easy to estimate and their coefficients are easy to interpret. Thus, our modeling approach provides one feasible way to generate insights into the structure of congressional collaborations (Martin, 2020). However, this feasibility comes with some potential weaknesses. First, whereas ERGMs and SAOMs have well-developed methods for estimating unbiased standard errors and p-values, logistic regression applied to network data does not. Here, we have attempted to overcome this weakness by using Monte Carlo p-values obtained by permuting the data using QAP, how${ }_{565}$ ever "Although QAP is known to be robust to [the presence of multicollinearity or third variable effects] in the OLS [ordinary least squares] case, there are no equivalent results for logistic regression" (Butts, 2019). Second, whereas ERGMs and SAOMs explicitly model the fact that each dyad is cross-nested in nodes and may appear in multiple triangles or other structures, logistic re50 gressions do not, which may lead to biased coefficient estimates. Although our models do not attempt to directly model such dependencies, our network-based goodness-of-fit assessments nonetheless suggest that the estimated coefficients do generate simulated networks that are similar to the observed network, which is a central goal of ERGM coefficient estimation (Stivala, 2020). Our efforts at 575 overcoming the weaknesses of logistic regression notwithstanding, we view our modeling approach as a feasible approach, but not necessarily an ideal one. The difficulties of estimating ERGMs and SAOMs in large, long-term, clustered empirical data such as these highlight an opportunity for the further development of these modeling approaches.

$580 \quad$ Future research may also benefit from exploring other factors that shape the formation of collaborations. Although we have focused on the role of party and gender, some recent research suggests the potential for gender-by-party interactions. For example, Thomsen (2015) attributes the small number of Republican women to the fact that women tend to be more liberal and lack what she calls 585 'party fit.' Therefore, while our models treat gender and party as independent and additive factors, future analyses may model them as interacting to explore the potential that gender-party intersections have unique collaboration-building dynamics (c.f., Reingold et al., 2019). Additionally, our models included state homophily as a control, which we find has an unexpectedly strong effect. Across 
Anzia, S. F., \& Berry, C. R. (2011). The jackie (and jill) robinson effect: Why do congresswomen outperform congressmen? American Journal of Political Science, 55, 478-493.

Aref, S., \& Neal, Z. P. (2020). Detecting coalitions by optimally partitioning

Baller, I. (2017). Specialists, party members, or national representatives: Patterns in co-sponsorship of amendments in the european parliament. European Union Politics, 18, 469-490.

Barnes, T. D. (2012). Gender and legislative preferences: Evidence from the 625

these 19 sessions, on average a legislator was more than 13 times more likely to collaborate with another legislator from the same state than with a legislator from a different state. While this is consistent with past research on spatial homophily in collaboration (Aleman \& Calvo, 2013; Bratton \& Rouse, 2011; Baller, 2017; Fischer et al., 2019), it is noteworthy that it exerts a stronger ffect than party and warrants further investigation. collaboration networks from bipartite bill co-sponsorship data, then used these networks to explore the role of party and gender in collaboration formation in the context of shifting party control. We find that party matters, but matters more for Republicans, and that gender matters, but matters more for women. Although legislators have many potentially competing identities including gender but also race, ethnicity, and religion, political party continues to play a particularly dominant role, which may create the conditions for deeper polarization and fewer opportunities for unity.

\section{Data availability statement}

All data and code necessary to replicate this study are available at https: //osf.io/xba82/.

\section{Disclosures}

The authors declare no conflicts of interest.

Aleman, E., \& Calvo, E. (2013). Explaining policy ties in presidential congresses: A network analysis of bill initiation data. Political Studies, 61, 356-377.

Andris, C., Lee, D., Hamilton, M. J., Martino, M., Gunning, C. E., \& Selden, J. A. (2015). The rise of partisanship and super-cooperators in the us house of representatives. PloS One, 10, e0123507.

argentine provinces. Politics and Gender, 8, 483-507. 
Brashears, M. E. (2008). Gender and homophily: Differences in male and female association in blau space. Social Science Research, 37, 400-415.

Brashears, M. E. (2015). A longitudinal analysis of gendered association patterns: Homophily and social distance in the general social survey. Journal of Social Structure, 16, 1.

Bratton, K. A., \& Rouse, S. M. (2011). Networks in the legislative arena: How group dynamics affect cosponsorship. Legislative Studies Quarterly, 36, 423460.

Breiger, R. L. (1974). The duality of persons and groups. Social Forces, 53, 181-190.

Butts, C. T. (2019). sna: Tools for Social Network Analysis. URL: https: //CRAN.R-project.org/package=sna $\mathrm{r}$ package version 2.5.

Caldeira, G. A., \& Patterson, S. C. (1987). Political friendship in the legislature. The Journal of Politics, 49, 953-975.

${ }_{640}$ Campbell, J. E. (1982). Cosponsoring legislation in the us congress. Legislative Studies Quarterly, (pp. 415-422).

Clark, J. H., \& Caro, V. (2013). Multimember districts and the substantive representation of women: An analysis of legislative cosponsorship networks. Politics Gender, 9, 1-30.

Cook, J. M. (2011). Gender, voting and cosponsorship in the maine state legislature. New England Journal of Political Science, 6, 2-30.

Craig, A., Cranmer, S. J., Desmarais, B. A., Clark, C. J., \& Moscardelli, V. G. (2018). The role of race, ethnicity, and gender in the congressional cosponsorship network. arXiv:1512.06141, .

Desmarais, B. A., \& Cranmer, S. J. (2012a). Statistical inference for valued-edge networks: The generalized exponential random graph model. PLOS ONE, 7, 1-12. doi:10.1371/journal pone.0030136.

Desmarais, B. A., \& Cranmer, S. J. (2012b). Statistical mechanics of networks: Estimation and uncertainty. Physica A: Statistical Mechanics and its Applications, 391, 1865-1876.

Desmarais, B. A., Moscardelli, V. G., Schaffner, B. F., \& Kowal, M. S. (2015). Measuring legislative collaboration: The senate press events network. Social Networks, 40, 43-54.

Domagalski, R., Neal, Z., \& Sagan, B. (2021a). backbone: Extracts the Backbone from Weighted Graphs. URL: https://CRAN.R-project.org/package= backbone $\mathrm{R}$ package version 1.3.0. 
Domagalski, R., Neal, Z. P., \& Sagan, B. (2021b). Backbone: An R package for extracting the backbone of bipartite projections. PLOS ONE, 16, e0244363. doi:10.1371/journal pone. 0244363.

Finke, D. (2012). Proposal stage coalition-building in the european parliament. European Union Politics, 13, 487-512.

Fischer, M., Varone, F., Gava, R., \& Sciarini, P. (2019). How mps ties to interest groups matter for legislative co-sponsorship. Social Networks, 57, 34-42.

Fong, C. (2020). Expertise, networks, and interpersonal influence in congress. The Journal of Politics, 82, 269-284.

Fouirnaies, A., Hall, A. B., \& Payson, J. (2019). Understanding the legislative gender gap: Evidence from u.s. states, .

Fowler, J. H. (2006a). Connecting the congress: A study of cosponsorship networks. Political Analysis, 14, 456-487.

675 Fowler, J. H. (2006b). Legislative cosponsorship networks in the us house and senate. Social Networks, 28, 454-465.

Gagliarducci, S., \& Paserman, M. D. (2016). Gender differences in cooperative environments? evidence from the us congress. NBER Working Paper, .

Grossmann, M., \& Hopkins, D. A. (2015). Ideological republicans and group interest democrats: The asymmetry of american party politics. Perspectives on Politics, 13, 119.

Highton, B., \& Rocca, M. S. (2005). Beyond the roll-call arena: The determinants of position taking in congress. Political Research Quarterly, 58, 303-316. doi:10.1177/106591290505800210.

Holm, S. (1979). A simple sequentially rejective multiple test procedure. Scandinavian Journal of Statistics, 6, 65-70.

Hong, Y. (2013). On computing the distribution function for the poisson binomial distribution. Computational Statistics and Data Analysis, 59, 41-51.

Hunter, D. R., Handcock, M. S., Butts, C. T., Goodreau, S. M., \& Morris, M. (2008). ergm: A package to fit, simulate and diagnose exponential-family models for networks. Journal of Statistical Software, 24, nihpa54860.

Ingraham, C. (2015). A stunning visualization of our divided congress. Washington Post, . URL: https://www .washingtonpost. com/news/wonk/wp/2015/ 04/23/a-stunning-visualization-of-our-divided-congress/.

695 Kessler, D., \& Krehbiel, K. (1996). Dynamics of cosponsorship. The American Political Science Review, 90, 555-566. 
Kirkland, J. H. (2011). The relational determinants of legislative outcomes: Strong and weak ties between legislators. The Journal of Politics, 73, 887898.

Kirkland, J. H. (2014). Chamber size effects on the collaborative structure of legislatures. Legislative Studies Quarterly, 39, 169-198.

Kirkland, J. H., \& Gross, J. H. (2014). Measurement and theory in legislative networks: The evolving topology of congressional collaboration. Social Networks, 36, 97 - 109. Special Issue on Political Networks.

Koger, G. (2003). Position taking and cosponsorship in the us house. Legislative Studies Quarterly, 28, 225-246.

Koger, G., Masket, S., \& Noel, H. (2016). No disciplined army: American political parties as networks. In J. N. Victor, A. H. Montgomery, \& L. M. (Eds.), The Oxford Handbook of Political Netwokrs chapter 18. (pp. 453-470). Oxford: Oxford University Press.

Layman, G. C., Carsey, T. M., \& Horowitz, J. M. (2006). Party polarization in american politics: Characteristics, causes, and consequences. Annu. Rev. Polit. Sci., 9, 83-110.

Liebig, J., \& Rao, A. (2016). Fast extraction of the backbone of projected bipartite networks to aid community detection. Europhysics Letters, 113, 28003.

Lovenduski, J. (1998). Gendering research in political science. Annual Review of Political Science, 1, 333-356.

Martin, J. L. (2020). Comment on geodesic cycle length distributions in delusional and other social networks. Journal of Social Structure, 21, 77-93.

McCarty, N. (2014). What we know and don't know about our polarized politics. Washington Post, . URL: https: //www . washingtonpost . com/news/monkey-cage/wp/2014/01/08/ what-we-know-and-dont-know-about-our-polarized-politics/.

McPherson, M., Smith-Lovin, L., \& Cook, J. M. (2001). Birds of a feather: Homophily in social networks. Annual Review of Sociology, 27, 415-444.

Micozzi, J. P. (2014). Alliance for progress? multilevel ambition and patterns of cosponsorship in the argentine house. Comparative Political Studies, 47 , 1186-1208.

${ }_{730}$ Moody, J., \& Mucha, P. J. (2013). Portrait of political party polarization. Network Science, 1, 119-121.

Nagelkerke, N. J. (1991). A note on a general definition of the coefficient of determination. Biometrika, 78, 691-692. 
Neal, Z. P. (2014). The backbone of bipartite projections: Inferring relationships from co-authorship, co-sponsorship, co-attendance and other co-behaviors. Social Networks, 39, 84-97.

Neal, Z. P. (2020). A sign of the times? weak and strong polarization in the u.s. congress, 1973-2016. Social Networks, 60, 103-112.

Neal, Z. P., Domagalski, R., \& Sagan, B. (In press). Analysis of spatial networks from bipartite projections using the R backbone package. Geographical Analysis, 0. doi:https://doi.org/10.1111/gean.12275.

Orstein, N. (2014). Yes, polarization is asymmetricand conservatives are worse. The Atlantic, . URL: https://www.theatlantic.com/politics/archive/2014/06/

745 yes-polarization-is-asymmetric-and-conservatives-are-worse/ 373044/.

Papavero, L. C., \& Zucchini, F. (2018). Gender and party cohesion in the italian parliament: A spatial analysis. Italian Political Science Review/Rivista Italiana di Scienza Politica, 48, 243-264.

Porter, M. A., Mucha, P. J., Newman, M. E., \& Warmbrand, C. M. (2005). A network analysis of committees in the us house of representatives. Proceedings of the National Academy of Sciences, 102, 7057-7062.

Reingold, B., Widner, K., \& Harmon, R. (2019). Legislating at the intersections: Race, gender, and representation. American Politics, .

755 Ringe, N., N., V. J., \& H., G. J. (2013). Keeping your friends close and your enemies closer? information networks in legislative politics. British Journal of Political Science, 43, 601-628.

Ringe, N., Victor, J. N., \& Cho, W. T. (2016). Legislative networks. In J. N. Victor, A. H. Montgomery, \& L. M. (Eds.), The Oxford Handbook of Political Netwokrs chapter 19. (pp. 471-490). Oxford: Oxford University Press.

Rippere, P. S. (2016). Polarization reconsidered: Bipartisan cooperation through bill cosponsorship. Polity, 48, 243-278.

Russell, A. (2021). Gendered priorities? policy communication in the us senate. Congress \& the Presidency, (pp. 1-24).

765 Saracco, F., Di Clemente, R., Gabrielli, A., \& Squartini, T. (2015). Randomizing bipartite networks: the case of the world trade web. Scientific Reports, 5, 10595. doi:10.1038/srep10595.

Saracco, F., Straka, M. J., Di Clemente, R., Gabrielli, A., Caldarelli, G., \& Squartini, T. (2017). Inferring monopartite projections of bipartite networks: an entropy-based approach. New Journal of Physics, 19, 053022. 
Schiller, W. J. (1995). Senators as political entrepreneurs: Using bill sponsorship to shape legislative agendas. American Journal of Political Science, 39, 186203.

Schmitt, C., \& Brant, H. K. (2019). Gender, ambition, and legislative behavior in the united states house. Journal of Women, Politics, and Policy, 40, $286-308$.

Schoch, D., \& Brandes, U. (2020). Positions to niches: Interval representations of co-voting behavior. Scientific Reports, .

Schwindt-Bayer, L. A. (2006). Still supermadres? gender and the policy priorities of latin american legislators. American Journal of Political Science, 50, $570-585$.

Shim, J. (2020). Gender politics and legislative networks in taiwan: An analysis of women-bill co-sponsorship and bill success. Parliamentary Affairs, .

Shim, J. (2021). Substantive representation of women and policy-vote tradeoffs: does supporting women's issue bills decrease a legislator's chance of reelection? The Journal of Legislative Studies, (pp. 1-21).

Snijders, T. A. (1996). Stochastic actor-oriented models for network change. Journal of mathematical sociology, 21, 149-172.

Spirou, M. E. (2017). The challenges of political representation: Gender in a us state legislature. International Journal of Public Leadership, .

Stivala, A. (2020). Geodesic cycle length distributions in delusional and other social networks. Journal of Social Structure, 21, 35-76.

Swers, M. L. (1998). Are women more likely to vote for women's issue bills than their male colleagues? Legislative Studies Quarterly, 23, 435-448.

Swers, M. L. (2005). Connecting descriptive and substantive representation: An analysis of sex differences in cosponsorship activity. Legislative Studies Quarterly, 30, 407-433.

Tam, C., Wendy, K., \& Fowler, J. H. (2010). Legislative success in a small world: Social network analysis and the dynamics of congressional legislation. The Journal of Politics, 72, 124-135.

Thomsen, D. M. (2015). Why so few (republican) women? explaining the partisan imbalance of women in the us congress. Legislative Studies Quarterly, 40, 295-323.

Thomsen, D. M., \& King, A. S. (2020). Women's representation and the gendered pipeline to power. American Political Science Review, 114, 989-1000. 
Volden, C., Wiseman, A. E., \& Wittmer, D. E. (2013). When are women more effective lawmakers than men? American Journal of Political Science, 57, 326-341.

Wang, P., Pattison, P., \& Robins, G. (2013). Exponential random graph model specifications for bipartite networks - a dependence hierarchy. Social networks, 35, 211-222.

Wangnerud, L. (2009). Women in parliaments: Descriptive and substantive representation. Annual Review of Political Science, 12, 51-69.

Wilson, R. K., \& Young, C. D. (1997). Cosponsorship in the us congress. Legislative Studies Quarterly, 22, 25-43.

Wojcik, S., \& Mullenax, S. (2017). Men idle, women network: How networks help female legislators succeed. Legislative Studies Quarterly, 42, 579-610.

Zhang, Y., Friend, A. J., Traud, A. L., Porter, M. A., Fowler, J. H., \& Mucha, P. J. (2008). Community structure in congressional cosponsorship networks. Physica A: Statistical Mechanics and Its Applications, 387, 1705-1712. 